\title{
Analysis of the Energy Flexibility of Residential Buildings in the Heating and Cooling Season
}

\author{
Jacopo Vivian ${ }^{1}$, Umberto Chiodarelli ${ }^{1}$, Giuseppe Emmi ${ }^{1}$, Angelo Zarrella ${ }^{1}$ \\ ${ }^{1}$ University of Padova, Dept. of Industrial Engineering, via Venezia, 1 - 35131 Padova (Italy)
}

\begin{abstract}
The present paper evaluates the potential of using the thermal inertia of building structures to shift their heat load pattern, i.e. to participate to Active Demand Response (ADR) programs. The methodology adopted relies on two energy flexibility indicators proposed by previous researchers: the available storage capacity for demand response $\left(C_{a d r}\right)$ and the efficiency of the ADR event $\left(\eta_{a d r}\right)$. The study analyses the effect of the building envelope, the user behaviour and the installed capacity of the heating system on the flexibility indicators for three reference apartments -from the 70s, 90s and recently built- in both heating and cooling season. The results show that the available storage capacity increases with the design thermal load of the considered building, i.e. it increases from new to old buildings. However, part of the thermal energy shifted is lost through the envelope after the ADR events, resulting in lower efficiencies for old buildings. In general, upwards and downwards modulation events are preferable just before and just after the peak load periods, respectively. The paper shows that severe weather conditions and intermittent setpoint schedules lead to exceptions to this general rule. Moreover, the indicators were used to evaluate the energy flexibility of the considered buildings in the summer season. Here, the choice of the best ADR events is more difficult due to the high variability of diurnal heat gains, especially in buildings with low thermal insulation.
\end{abstract}

\section{Introduction}

Nowadays buildings are responsible of $36 \%$ of $\mathrm{CO}_{2}$ emissions and space heating and cooling alone accounts for $40 \%$ of the final energy consumption at European level (EU, 2018). The 2015 Paris Agreement on Climate Change following the COP21 Conference boosted the European Union's efforts to decarbonise its building stock. As a result, the European Commission presented in November 2016 the Clean Energy Package (EU, 2016), i.e. a set of measures aimed at regulating the clean energy transition. The first document to be approved was the new Directive 2018/844 on the energy performance of buildings (EU, 2018). The Directive introduces a framework to calculate the smart readiness of buildings, in order to assess the capabilities of a building (or building unit) to adapt its operation to the needs of the occupants and of the grid and to improve its energy efficiency and overall performance. This capability is strongly related to the so-called "energy flexibility" of buildings, i.e. to their "..ability to manage its demand and generation according to local climate conditions, user needs and grid requirements", as defined by the research group of the IEA EBC Annex 67 (Jensen et al, 2017). The energy flexibility of buildings will thus allow for demand response based on the requirements of an external actor, often named "aggregator". One of the most promising applications of ADR consists of using the thermal inertia of buildings and thermal energy storage systems to shift the load of electrically driven HVAC devices -such as heat pumps (Arteconi et al., 2014). Using the building structures alone or combined with existing heat storage systems is potentially disruptive, as no additional investment costs are needed but those for the "intelligence" and "connectivity" of existing HVAC control devices. In literature, different works studied the impacts of energy flexibility in buildings and one of the most debated topics is how to quantify this property. Some authors evaluated directly the performance of specific control strategies in terms of cost or energy savings, reduction of $\mathrm{CO}_{2}$ emissions or peak shaving just to name some of the most common key performance indicators (KPIs). For instance, Pau et al. (2018) proposed a smart control strategy formulated as a Mixed Integer Linear Programming (MILP) problem to reduce the peak load of a pool of heat pumps using hot water tanks as thermal buffers. The study assessed the sensitivity of such control strategy to variations of outdoor temperature, size of the storage tanks and number of houses involved in the optimization. Rodriguez et al. (2018) considered different scenarios of setpoint temperature and sixteen different control strategies in a plus-energy dwelling participating to a Demand Side Management (DSM) program, concluding that cost savings up to $25 \%$ could be achieved. A second approach consists of evaluating the energy flexibility of buildings by using specific indicators, thus making it possible to predict this property beforehand and at the same time to compare different buildings. Reynders et al. (2018) summarized six methodologies to quantify the energy flexibility of buildings. Among them, Nuytten et al. (2013) defined the energy flexibility as the amount of hours the energy supply system of the building can be delayed or forced to operate. D'Hulst et al. (2015) proposed to assess the energy flexibility as the possible power increase/decrease that can be realized at a certain time of day, combined with how long this power increase or decrease can be sustained without affecting thermal 
comfort inside the building. Stinner et al. (2016) suggested similar indicators, i.e. temporal and power - or energy - flexibility, but using a different process to calculate them. Two simulations are carried out, starting with the hot water storage tank at maximum and minimum "state of charge". They concluded that the available flexibility varies over time. De Coninck and Helsen (2016) evaluated the flexibility in their research using cost functions. They used a reference scenario in order to obtain the optimal system operation with respect to the operational costs. The methodology returns as output the amount of energy that can be shifted to or from a specified flexibility interval and the costs associated with this load shifting. Oldewurtel et al. (2013) extended the use of traditional performance indicators for storage systems such as the energy capacity, the maximum (dis)charge power and the autonomy - to demand response technologies. A similar approach was adopted by Reynders et al. (2018), who suggested to evaluate the energy flexibility by the use of three indicators: the available storage capacity, the storage efficiency and the power shifting potential. The methodology used to obtain these indicators has been used in this paper and will be therefore thoroughly described in the methodological section. A recent paper by Foteinaki et al. (2018) investigated the energy flexibility of low-energy residential buildings. They concluded that the latter is determined primarily by the heat losses to the external ambient and by the thermal capacity of the internal walls rather than by the concrete thickness of external walls.

The present work aims at evaluating how different boundary conditions - e.g. time of ADR event, weather conditions and user behavior - affect the energy flexibility of three apartments representative of the Italian residential building stock in both heating and cooling season.

\section{Methods}

The literature review showed that several methods for assessing the energy flexibility of building structures have already been proposed in recent years. Among them, the method proposed by Reynders et al. (2017) was chosen due to its reduced computational effort and the easy interpretation of the related KPIs.

The method relies on two simulations: a reference simulation and a so-called ADR simulation, i.e. a simulation where an ADR event occurs. An ADR event is a time-limited change in the boundary conditions that affects both the thermal comfort of the indoor environment and the energy consumption pattern of the building. This change can be a reduction or an increment in the schedule of the temperature (and eventually also humidity) setpoint at certain hour of the day.

For example, a reference simulation calculates the heating energy demand of a building with a predefined schedule of setpoint temperature and occupancy patterns, and the ADR simulation determines the energy demand of the same building with an increase or a decrease of the setpoint temperatures for two hours every three days at 4 am, as shown in Figure 1.
The thermal load profiles obtained with the simulations are then used to calculate two flexibility indicators. The first one, called available capacity for active demand response, is defined as follows:

$$
C_{a d r}=\int_{0}^{l_{a d r}}\left(Q_{a d r}-Q_{r e f}\right) d t
$$

where $Q_{\text {ref }}$ is the heat load profile of the building in the reference simulation, $Q_{a d r}$ is the energy demand in the ADR simulation and $l_{a d r}$ is the duration of the event. $C_{a d r}$ measures the surplus/deficit of energy stored in the building during the ADR event, which can be considered as the capacity of a virtual thermal storage system.

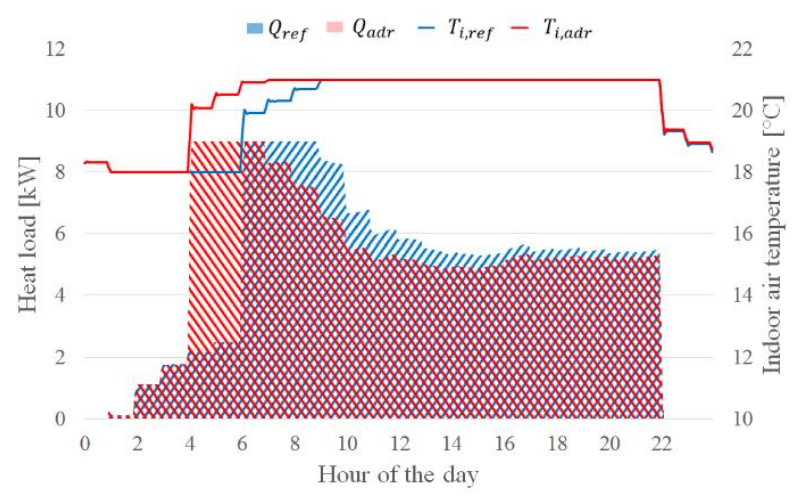

Figure 1: Thermal load profile of a building in the reference (blue) and ADR (red) simulation scenarios.

In case the temperature setpoint is increased during heating mode (upwards modulation), only part of the energy surplus will be used after the event to reduce the energy consumption of the building. A similar argument holds true for downwards modulation events such as the decrease of the temperature setpoint in winter: the energy spent after the ADR event is higher than the energy saved due to the forced shutdown during the ADR event. Therefore, the second indicator measures the "efficiency" of the virtual thermal storage, defined as follows:

$$
\eta_{a d r}=1-\frac{\int_{0}^{\infty}\left(Q_{a d r}-Q_{r e f}\right) d t}{\left|\int_{0}^{l_{a d r}}\left(Q_{a d r}-Q_{r e f}\right) d t\right|}
$$

As discussed in Pean et al., (2018), the ADR efficiency of the virtual storage $\eta_{a d r}$ can be interpreted as the ratio between the "rebound effect" and the "ADR event", i.e. the difference between the energy needs of the building after and during the ADR event. As a corollary of this definition, one may conclude that any ADR event involves a certain loss of energy.

The duration of the ADR events $l_{a d r}$ is set to 2 hours. This choice follows the conclusions of Reynders et al. (2017), who found it to be a good compromise between low energy losses and high available storage capacity. Secondly, three days were chosen for the calculations of the numerator of $\eta_{a d r}$ in Equation (2). In fact, a postprocessing analysis revealed that for all the considered buildings the rebound effect after 72 hours has almost ceased. This is important to ensure that consecutive events do not influence each other. The other assumptions are the following: 
- The energy needs were calculated using a fixed indoor air temperature (according to the setpoint schedules) and the maximum limit on the thermal power was calculated according to the Standard EN 12831 (CEN, 2017) (20\% being set as radiative and $80 \%$ convective) with and without shifting power;

- The shifting power in the heating season was set according to the EN 12831 Standard- using 2 hours for recovery duration and the inactivity temperature drops are $2 \mathrm{~K}$ for $\mathrm{BN}$ and $3 \mathrm{~K}$ for $\mathrm{B} 90$ and $\mathrm{BN}$.

- The cooling power was set to $7.5 \mathrm{~kW}$ for all cases, corresponding to the typical size of a split system with three internal units;

- The weather data is taken from the Test Reference Year of Venice (DOE, 2005);

- The internal gains are divided in $30 \%$ radiative and $70 \%$ convective contributions;

- In summer an internal generation of $9 \mathrm{~kg} / \mathrm{day}$ of water vapour was set as an average value for residential buildings;

- Summer and winter simulations were carried out separately to avoid variations in the boundary conditions.

Furthermore, three different types of building structures were considered, differing by type of external walls and windows, as described in the next paragraph. Lastly, for each type of building two different schedules of indoor air setpoint temperature and internal heat gains were used to simulate different behavior of the users -see Figure 2. The schedules are intended to represent the continuous occupancy typical of old couples (OC) and the discontinuous occupancy of young families (FAM).
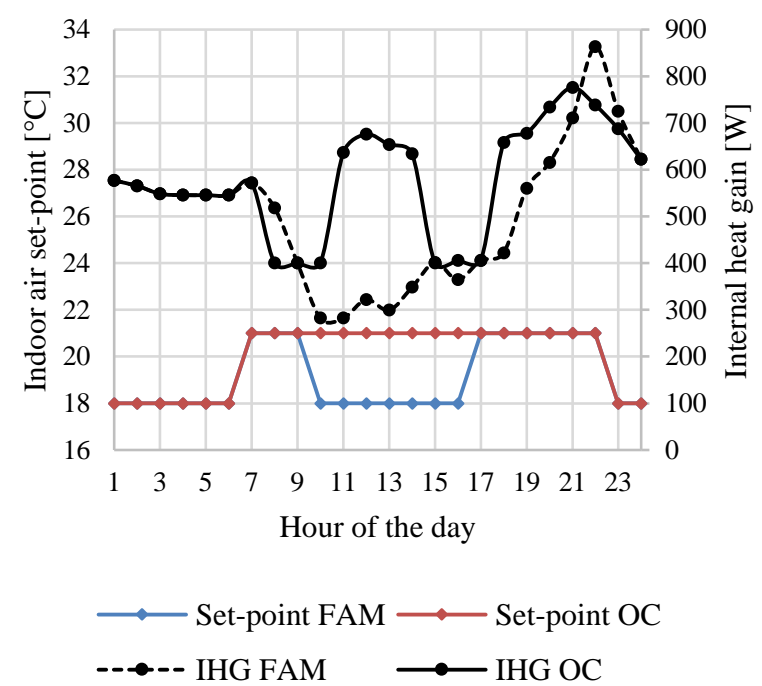

Figure 2: Boundary conditions for the simulations of the heating season: temperature setpoints and internal heat gains for two occupancy patterns (FAM and OC)

The schedules, resumed in Figure 2, are deterministic and were built using the work of Barthelmes et al. (2015) and the Standard EN 16798 (CEN, 2015) as starting points. In summer, the reference heat load profile was calculated using a constant setpoint temperature of $26^{\circ} \mathrm{C}$ and the internal heat gains of the schedule FAM.

\section{Description of the case studies}

\section{Building types}

Table 1 summarizes the properties of the three building types B70, B90 and BN. They have typical thermal insulation of houses built in the 70s, 90s and after 2005 respectively, according to the corresponding Standards in force at time of construction. They have an internal floor area of $94.4 \mathrm{~m}^{2}$ with two external walls in the west and in the east direction. The apartment lays on a portico, which makes the pavement an additional external surface. The other surfaces are adjacent to other neighbors lodgings; thus, they have been considered adiabatic.

Table 1: Thermal properties of the building.

\begin{tabular}{|l|c|c|c|}
\hline \multirow{2}{*}{ Building elements } & \multicolumn{3}{|c|}{ Thermal transmittance U } \\
\cline { 2 - 4 } & $\left.\left.\mathbf{B} / \mathbf{m}^{\mathbf{2}} \mathbf{K}\right)\right]$ \\
\hline External walls & 1.14 & $\mathbf{B 9 0}$ & $\mathbf{B N}$ \\
\hline Dividing walls & 1.41 & 1.41 & 0.32 \\
\hline Internal walls & 2.11 & 2.11 & 1.41 \\
\hline Ceiling (inter-storey) & 1.58 & 1.58 & 1.58 \\
\hline Floor & 1.61 & 0.68 & 0.38 \\
\hline Windows & 2.75 & 2.75 & 1.53 \\
\hline
\end{tabular}

\section{Types of ADR events}

During the heating season, all the events consist in an increase/drop in the indoor air temperature setpoint of +/$3 \mathrm{~K}$ compared to the reference schedule. The upwards flexibility events are placed when temperature in the reference schedule is $18^{\circ} \mathrm{C}$. Similarly, downwards flexibility events during the heating season take place only when the setpoint temperature in the reference schedule is $21^{\circ} \mathrm{C}$. Table 2 summarizes the events chosen for the simulations. Notice that most events were located at the end or at the beginning of the periods with presumed presence of the occupants (i.e. with the setpoint at $21^{\circ} \mathrm{C}$ ), and that at least one event was chosen in the middle of the "occupied" period.

Table 2: Summary of ADR events during heating season.

\begin{tabular}{|l|c|c|}
\hline Type of ADR events & \multicolumn{2}{|c|}{ Hours of the day } \\
\cline { 2 - 3 } during the heating season & FAM & OC \\
\hline \multirow{2}{*}{$\begin{array}{l}\text { UP (upwards modulation): } \\
\text { increments of the setpoint } \\
\text { temperature }\end{array}$} & $4-6$ & $0-2$ \\
\cline { 2 - 3 } & $9-11$ & $4-6$ \\
\cline { 2 - 3 } & $12-14$ & $22-24$ \\
\hline \multirow{2}{*}{$\begin{array}{l}\text { DOWN (downwards } \\
\text { modulation): increments of } \\
\text { the setpoint temperature }\end{array}$} & $14-16$ & \\
\cline { 2 - 3 } & $17-19$ & $8-10$ \\
\hline
\end{tabular}

In summer six ADR events (one every six hours, starting from midnight) were selected to thoroughly picture the flexibility of the buildings under different conditions. In fact, the cooling load changes significantly during the day due to the presence of the solar radiation. The relative humidity setpoint during the events has been increased to $60 \%$ during the upwards flexibility events (point B in Fig. 3 ) and reduced to $45 \%$ during downwards flexibility events (point $\mathrm{C}$ in Fig. 3) in order to reduce the latent heat load during the events and at the same time to operate 
within the limits of the thermal comfort. Indeed, with these values, a $-0.5<\mathrm{PMV}<+0.5$ can be achieved with a clothing thermal resistance equal to 0.5 clo according to the diagram of ASHRAE Standard 55 and ISO 7730 - see Figure 3. The ADR events are summarized in Table 3.



Figure 3: Indoor air boundary conditions in summer (source: ISO 7730, 2005).

Table 3: Summary of ADR events during cooling season.

\begin{tabular}{|c|c|}
\hline $\begin{array}{l}\text { Type of ADR events } \\
\text { during the cooling season }\end{array}$ & $\begin{array}{l}\text { Hours of the day when } \\
\text { the single event occurs }\end{array}$ \\
\hline \multirow{6}{*}{$\begin{array}{l}\text { UP (upwards modulation): } \\
\text { reduction of the setpoint } \\
\text { temperature }\end{array}$} & $0-2$ \\
\hline & $4-6$ \\
\hline & $8-10$ \\
\hline & $12-14$ \\
\hline & 16-18 \\
\hline & $20-22$ \\
\hline \multirow{6}{*}{$\begin{array}{l}\text { DOWN (downwards } \\
\text { modulation): increments } \\
\text { of the setpoint temperature }\end{array}$} & $0-2$ \\
\hline & $4-6$ \\
\hline & $8-10$ \\
\hline & $12-14$ \\
\hline & $16-18$ \\
\hline & $20-22$ \\
\hline
\end{tabular}

From all these considerations, 84 simulations (12 reference simulations and 72 with ADR events) were performed to characterize the energy flexibility of the considered buildings in the heating season and 39 simulations ( 3 reference simulations and 36 with ADR events) in the cooling one.

\section{Results}

\section{Effect of building type}

Table 4 shows the average monthly $C_{a d r}$ for the events UP 4-6 and DOWN 13-15 in the winter season and for events UP 4-6 and DOWN 8-10 in the cooling season with an OC schedule. Here $C_{a d r}$ is expressed in terms of average thermal power $\left(\mathrm{kWh} / h_{a d r}\right)$, i.e. as the ratio between the available storage capacity and the duration of the events ( 2 hours each for our case studies). Therefore, $C_{a d r}$ represents the average thermal power shifted by the building in a month during the hours of event. The results show that the power shifted decreases from the winter season to the mid-season as a consequence of a lower heat demand, in particular for the new building that has almost no energy needs during mild months.

As far as summer events are concerned, the peaks in all upwards cases are reached in the warmest month (July), with an average power shifted of almost $5 \mathrm{~kW}$. In milder months (June and August) the values tend to decrease, especially for buildings B90 and B70, due to the low thermal insulation and the possibility of free cooling during the night. The downwards modulation events (increase of the setpoint temperature) show a lower heat storage capacity compared to upwards events, with an average power shifted of around $2 \mathrm{~kW}$ in July. As far as the efficiency of the events is concerned, Figure 4 shows that the trend does not change from heating (a) to cooling (b) season: the annual average efficiency grows with increasing thermal insulation level of the building envelope.

Table 4: Average $C_{a d r}[\mathrm{kWh} / \mathrm{h}]$ per month of upwards and downwards modulation events in the heating season and cooling season.

\begin{tabular}{|c|c|c|c|c|c|c|}
\hline \multirow{2}{*}{ Month } & \multicolumn{3}{|c|}{$\begin{array}{c}\text { Upwards } \\
\text { modulation }\end{array}$} & \multicolumn{3}{c|}{$\begin{array}{c}\text { Downwards } \\
\text { modulation }\end{array}$} \\
\cline { 2 - 7 } & B70 & B90 & BN & B70 & B90 & BN \\
\hline 1 & 6.8 & 6.3 & 3.0 & -5.8 & -3.1 & -1.1 \\
\hline 2 & 7.6 & 5.9 & 2.5 & -4.6 & -2.1 & -0.5 \\
\hline 3 & 6.9 & 4.8 & 1.4 & -3.1 & -1.1 & -0.1 \\
\hline 4 & 4.3 & 2.1 & 0.0 & -1.1 & -0.2 & 0.0 \\
\hline 5 & - & - & -4.2 & - & - & - \\
\hline 6 & -2.9 & -3.5 & -4.6 & 0.1 & 0.1 & 0.2 \\
\hline 7 & -4.8 & -4.8 & -5.0 & 0.3 & 0.2 & 0.4 \\
\hline 8 & -4.0 & -4.5 & -5.0 & 0.0 & 0.0 & 0.2 \\
\hline 9 & - & - & -4.5 & - & - & - \\
\hline 10 & 3.6 & 1.8 & 0.0 & -0.9 & -0.1 & 0.0 \\
\hline 11 & 7.1 & 4.7 & 1.5 & -3.7 & -1.7 & -0.4 \\
\hline 12 & 7.1 & 5.6 & 2.4 & -5.0 & -2.7 & -0.9 \\
\hline
\end{tabular}

\section{Effect of type of ADR event}

This section shows that the available storage capacity and the efficiency of the ADR events depend on the temporal distance from high energy demand hours and on the maximum power of the heating or cooling system. Figure 5 shows, for instance, an example of the first effect on an upwards modulation event occurring in February in the B90 building. In Figure 5(a), the event occurs before the peak load hours (4-6) and in Figure 5(b) the forced startup occurs at the beginning of the night, when the setpoint is decreased and there is no heat demand. In the first case, the heating system is switched on when the indoor temperature has reached a low value (close to $18^{\circ} \mathrm{C}$ ), i.e. when all the heat stored in the building during the previous day has been discharged. Therefore, in this event the building structure can be used as a thermal reserve to store the heat for the following hours, thus leading to a high value of $C_{a d r}$. Then, the stored heat is quickly used after the event for flattening the morning peak load and the heating demand in the next hours, thus leading to an efficient ADR event (high values of $\eta_{a d r}$ ). The UP 22-24 case, instead, is one of the worst cases among the upwards modulation events. In fact, the surplus of thermal energy 
supplied to the building is low due to the high state of charge of the building during the event. This small amount of heat is wasted during the night, i.e. it is not efficiently used to shift the heat load (low values of $\eta_{\text {adr }}$ ).



Figure 4: Average $\eta_{a d r}$ in (a) heating and (b) cooling.

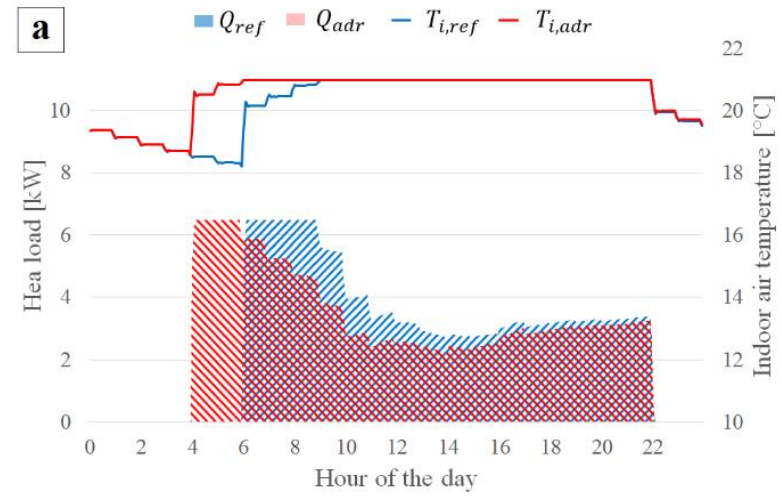

b

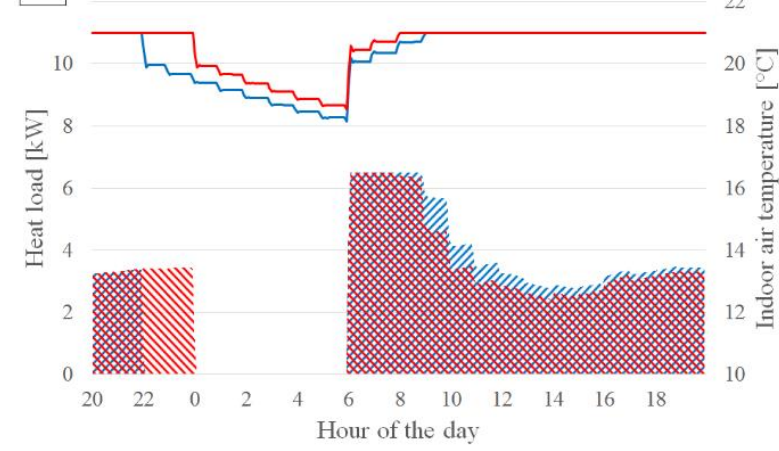

Figure 5: Heat load profiles of the ADR events for (a) UP 4-6 and (b) UP 22-24.

A limited thermal power of the heating system has two negative impacts on the energy flexibility indicators. The first effect is trivial: since less energy can be stored in the building during upwards modulation events, the available storage capacity is lower. On the other hand, the increase of indoor air temperature occurs more slowly and the setpoint is reached later, thus increasing the energy demand during off-peak hours. Consequently, the difference between the heat load profiles with and without ADR events is lower when the thermal power is limited. These effects contribute to the reduction of $C_{a d r}$ and $\eta_{a d r}$ during winter and especially for buildings with low thermal insulation. Both effects can be seen clearly in building B70 by comparing Figures 6(a) and 6(b).


Figure 6: Influence of the design thermal power: (a) without and (b) with shift power.

All the previous considerations hold true for downwards modulation events. The best temporal position of forced setpoint reductions takes place when the internal temperature has just reached $21^{\circ} \mathrm{C}$, i.e. immediately after the peak load. In fact, DOWN 8-10 is always the best performing event with regard to both flexibility indicators. Here, the deficit of energy is promptly compensated by an increase of consumption to reach and maintain $21^{\circ} \mathrm{C}$ compared to the reference simulation. During low consumption hours and in particular during the night, the potential increase of the building energy demand after the event is negligible, especially in highly insulated buildings. The energy flexibility indicators of downwards modulation events are also affected by the limitation of power of the heating system, especially for B90 and B70 in the winter season for the same reason explained above. The previous considerations hold true in the cooling season. However, during summer the peak load hour varies day by day depending primarily on the amount of solar radiation entering the building that in turn 
depends on the orientation of the glazed surfaces. For example, Figure 7 shows the cooling load of building BN in a day of June and a day of July. Obviously, the higher the cooling load, the higher the power that can be shifted in time by a forced switch-off of the HVAC system.
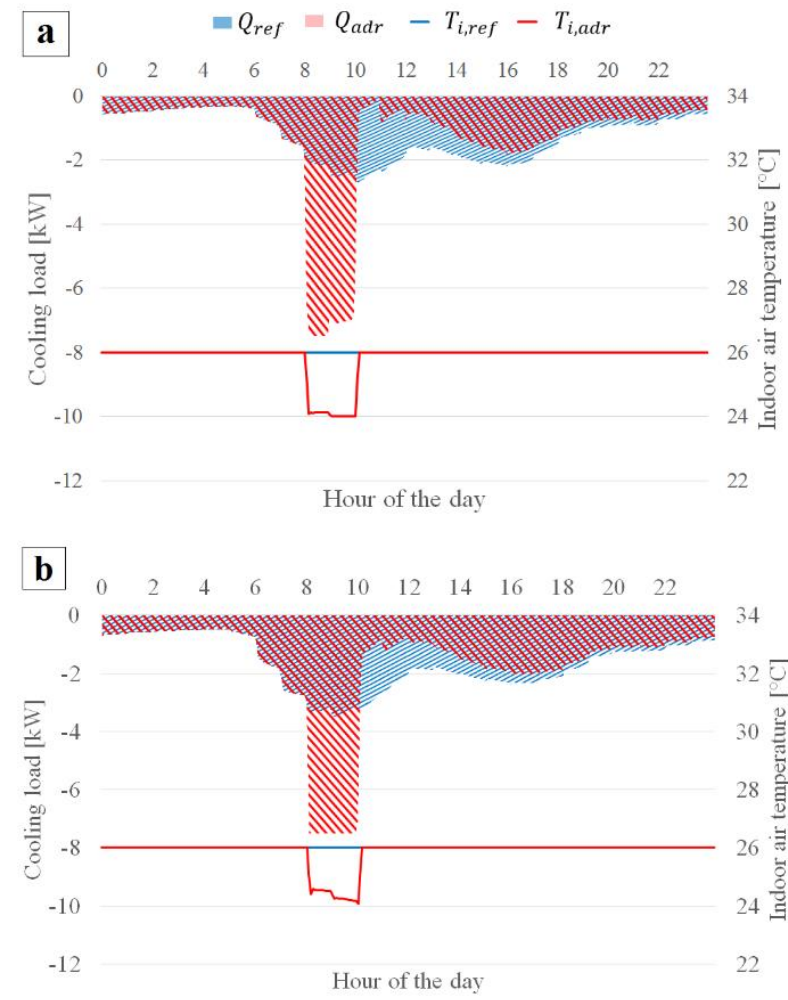

Figure 7: Upwards modulation events in the cooling season: a day of (a) June and (b) July.

Conversely, the efficiencies do not change significantly: they range from 90 to $92 \%$ in June, from 94 to $96 \%$ in July and from 93 to $96 \%$ in August for the new building. As explained in the previous Section, in the new building the cooling load is higher and spread during 24 hours instead of being limited to the daylight hours as for buildings B70 and B90.

\section{Effect of user behaviour}

For the schedule FAM, two peak load periods appear during the day: one in the morning, between 6 and 9 am, and one in the afternoon, between 4 and $7 \mathrm{pm}$. When the thermal power of the heating system includes the shift power, the upwards modulation events with the highest available storage capacity are UP 4-6 and UP 14-16. Thus, the aforementioned rules on the most favorable events hold true. However, the intermittent behavior imposed by the user reduces the efficiency of event UP 4-6 due to the diurnal temperature set back. Figure 8(a) shows, for instance, that all the heat stored in the building B90 during an event UP 4-6 in February is lost after 9 am. Moreover, the intermittent operation during the day imposed by schedule FAM increases the energy consumption during night hours even for buildings $\mathrm{B} 90$ and $\mathrm{BN}$ during the coldest months of the year. This change in the reference heat load pattern improves the performance of events occurring later, such as UP 9-11 and DOWN 19-21. With the OC schedule this happened only to uninsulated buildings in the coldest months of the year as shown in the previous paragraph. The FAM schedule extends this change to refurbished and new buildings, in particular when the thermal power of the heating plant is limited.
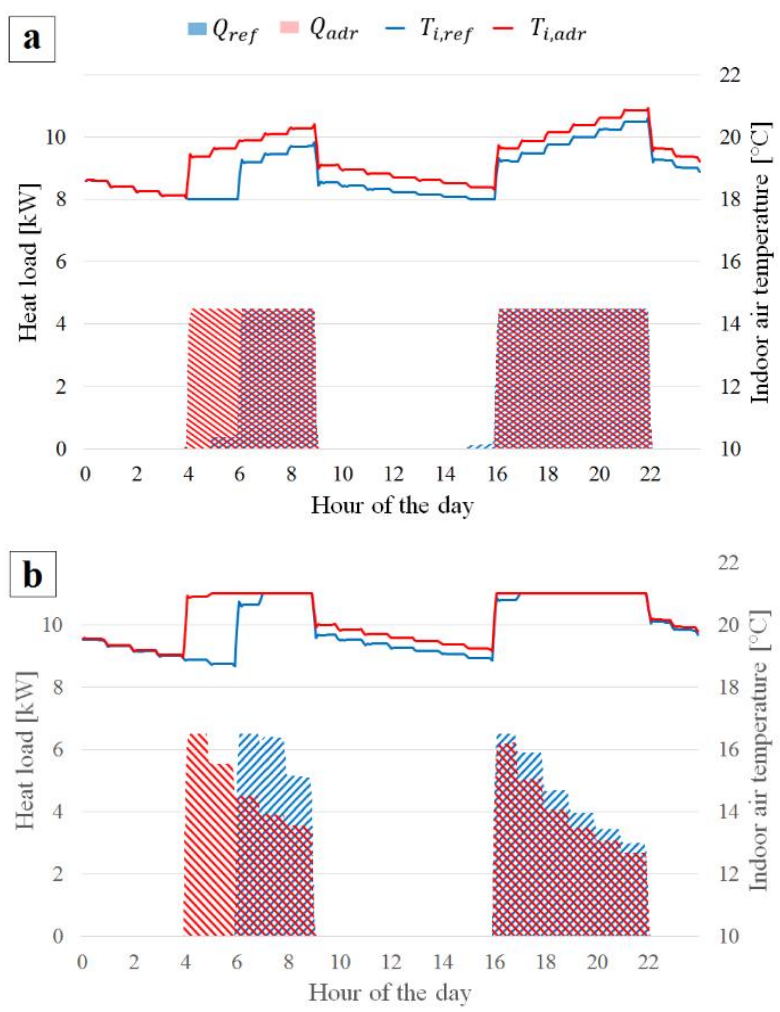

Figure 8: UP 4-6 event with FAM occupancy (a) without shift power, $(b)$ with shift power considered.

\section{Concluding discussion}

The energy shifting potential of three residential buildings was assessed through the energy flexibility indicators $C_{a d r}$ and $\eta_{a d r}$. They outline the potential energy stored or saved during the considered ADR events and how such amount of energy is effectively shifted to the following hours. The results have shown that $C_{a d r}$ decreases from old to new buildings during the heating season, while it increases in the cooling season -except in the month of July, when it is similar for all buildings. In both seasons, the better the insulation of the buildings, the higher the value of ADR efficiency. This means that, for upwards modulation events, the surplus of thermal energy "stored" in the building structure allows reducing the heat demand after the event in a more significant way for new buildings than for those with a poor thermal insulation.

As a rule of thumb, for upwards modulation events the higher $\eta_{a d r}$ values can be achieved when the events take place immediately before the high-consumption hours of the day, while $C_{a d r}$ tends to be higher at the end of lowconsumption periods. A similar rule was found for downwards modulation events: $\eta_{a d r}$ tends to be higher if the event is located immediately after the end of the peak hours of energy demand during the day and $C_{a d r}$ increases its value if the event takes place at the beginning of the occupation hours. 
The general rule did not hold true in the coldest months for buildings with low insulation, due to nocturnal startups of the HVAC devices. As a result, the best starting hours of the events were distant from the highconsumption hours. When the schedule was changed from OC to FAM type (more intermittent) and the nominal power of the heating system was reduced, these exceptions occurred also in more insulated buildings and during milder months.

In the cooling season, the general rule still applies but the choice of the best ADR events is more difficult due to the high fluctuation of diurnal heat gains, especially for buildings with low thermal insulation. In fact, the charge and discharge cycles are highly affected by the amount of solar radiation entering the building, that changes day by day depending on weather conditions and on the size and orientation of the glazed surfaces. In the downward modulation events during the cooling season, the value of $C_{a d r}$ of all events was very low compared to the upwards modulation cases.

The method used here to evaluate the energy flexibility offered by building structures has the following weaknesses: (i) the indicators deviate from the values calculated above when a thermostat control is included in the simulation, thus making these indicators unsuitable for real applications; (ii) for downwards modulation events, the definition of $\eta_{a d r}$ can be misleading, as higher thermal losses -and therefore higher consumption after the events- result in higher efficiency; (iii) the method does not consider thermal comfort issues, that could bring the users to prefer different ADR events from those indicated here as the best ones.

Nonetheless, the method provides a framework to assess the energy flexibility of buildings and seems therefore suitable for building energy labelling purposes. The results obtained in this article will be used in future research activities to evaluate the thermal behaviour of buildings within Active Demand Response policies at the level of both single building unit and district.

\section{Acknowledgements}

Project funded under the BIRD 2017 programme promoted by the University of Padova (year: 2017 - prot. BIRD177824).

\section{References}

Arteconi A., Hewitt N.J., Polonara F. (2013) Domestic demand-side management (DSM): Role of heat pumps and thermal energy storage (TES) systems. Applied Thermal Engineering 51, 155-165. doi:10.1016/j.applthermaleng.2012.09.023.

Barthelmes V.M., Becchio C., Corgnati S.P. (2016) Occupant behavior lifestyles in a residential nearly zero energy building: effect on energy use and thermal comfort. Science and Technology for the Built Environment 22, 960-75. doi:10.1080/23744731.2016.1197758.
D’Hulst R., Labeeuw W., Beusen B., Claessens S., Deconinck G., Vanthournout K. (2015) Demand response flexibility and flexibility potential of residential smart appliances: Experiences from large pilot test in Belgium. Applied Energy 155, 79-90. doi:10.1016/j.apenergy.2015.05.101.

De Coninck R., Helsen L. (2016) Quantification of flexibility in buildings by cost curves - Methodology and application. Applied Energy 162, 653-665. doi:10.1016/j.apenergy.2015.10.114.

European Union, Directive (EU) 2018/844 of the European Parliament and of the Council amending Directive 2010/31/EU on the Energy Performance of Buildings and Directive 2012/27/EU on Energy Efficiency. 30 May 2018.

European Union: European Commission. Communication from the Commission to the European Parliament, the Council, the European Economic and Social Committee, the Committee of the Regions and the European Investment Bank: Clean Energy For All Europeans, 30 November 2016, COM(2016) 860 final

European Committee for Standardization (2017) Energy performance of buildings-Method for the calculation of the design heat load - Part 1: Space heating load (EN 12831).

European Committee for Standardization (2015) Energy performance of buildings - Part 1: Indoor environmental input parameters for design and assessment of energy performance of buildings addressing indoor air quality, thermal environment, lighting and acoustics (prEN 16798-1).

Foteinaki K., Li R., Heller A., Rode C. (2018) Heating system energy flexibility of low-energy residential buildings. Energy \& Buildings 180 (2018) 95-108. doi: 10.1016/j.enbuild.2018.09.030.

International Organization for Standardization (2005) Ergonomics of the Thermal Environment - Analytical Determination and Interpretation of Thermal Comfort Using Calculation of the PMV and PPD Indices and Local Thermal Comfort Criteria (ISO 7730).

Jensen, S.O., Marszal-Pomianowska A., Lollini R., Pasut W. et al. (2017) IEA EBC Annex 67 Energy Flexible Buildings. Energy \& Buildings 155, 25-34. doi: 10.1016/j.enbuild.2017.08.044.

Klein, S.A. et al. (2010) TRNSYS 17: A Transient System Simulation Program, SolarEnergy Laboratory, University of Wisconsin, Madison (USA). http://sel.me.wisc.edu/trnsys.

Nuytten T., Claessens B., Paredis K., Van Bael J., Six D. (2013) Flexibility of a combined heat and power system with thermal energy storage for district heating. Applied Energy 104, 583-591. doi:10.1016/j.apenergy.2012.11.029.

Oldewurtel F., Sturzenegger D., Andersson G. et al. (2013) Towards a standardized building assessment 
for demand response. Proc. of 52nd IEEE annual Conference on Decision and Control (CDC 2013) 7083-8. Firenze (Italy) 10-13 Dec 2013.

Pau M., Cunsolo F., Vivian J., Ponci F., Monti A. (2018) Optimal scheduling of electric heat pumps combined with thermal storage for power peak shaving. Proc. of the 18th IEEE Intern. Conf. on Env. and El. Eng., EEEIC/I and CPS Europe 2018. Palermo (Italy), 1215 June 2018.

Péan T, Torres B, Salom J, Ortiz J. (2018) Representation of daily profiles of building energy flexibility. Proceedings from eSim 2018. Montreal (Canada), 910 May 2018.

Reynders G., Diriken J., Saelens D. (2017) Generic characterization method for energy flexibility: Applied to structural thermal storage in residential buildings. Applied Energy 198, 192-202. doi:10.1016/j.apenergy.2017.04.061.

Reynders G., Lopes R.A., Marszal-Pomianowska A., Aelenei D., Martins J., Saelens D. (2018) Energy flexible buildings: Energy flexible buildings: An evaluation of definitions and quantification methodologies applied to thermal storage. Energy \& Buildings 166, 372-390. doi: 10.1016/j.enbuild.2018.02.040.

Rodríguez L.R., Ramosa J.S., Domínguez S.A., Eicker U. (2018) Contributions of heat pumps to demand response: A case study of a plus-energy dwelling. Applied Energy 214, 191-204. doi:10.1016/j.apenergy.2018.01.086.

Stinner S., Huchtemann K., Müller D. (2016) Quantifying the operational flexibility of building energy systems with thermal energy storages. Applied Energy 181, 140-154. doi:10.1016/j.apenergy.2016.08.055.

U.S. Department of Energy (DOE). (2003) Energy Efficiency and Renewable Energy Division. Washington D.C. (USA) https://energyplus.net/weather/simulation (last access: 31/12/2018). 